\title{
Prevalence and factors associated with intestinal parasites among children of age 6 to 59 months in, Boricha district, South Ethiopia, in 2018
}

Berhan Tsegaye ${ }^{1 *}$, Amanuel Yoseph ${ }^{2}$ and Hunachew Beyene ${ }^{3}$

\begin{abstract}
Background: Intestinal parasites are the commonest cause of childhood diarrhea and malnutrition in Ethiopia. Information about intestinal parasites is the first fundamental step for designing intervention strategies against them. Hence, health planners can maximize their efforts. Information is scarce about intestinal parasites among children of under-five years of age in Boricha district. Therefore, this study aimed at assessing prevalence and factors associated with intestinal parasites among children of age 6 to 59 months in Boricha district, South Ethiopia.

Methods: A community based analytical cross sectional study was conducted among 624 children of age 6 to 59 months from January 1 to 30; in 2018. We have utilized two stage stratified sampling method. Firstly, simple random sampling was used to select sample Kebeles. Secondly, systematic random sampling method was used to select the study participants. Structured and interviewer administrated questionnaire was used to collect data. Parasitological examination of children's stool was conducted microscopically. Data were entered into Epi-info, exported and analyzed by SPSS version 22. Logistic regression analysis was conducted to identify association between explanatory variables and outcome variable. Adjusted Odds Ratio (AOR) with 95\% confidence interval $(95 \% \mathrm{Cl})$ was computed, and $P$-value $<0.05$ was considered as statistically significant. Descriptive statistics was presented using texts, tables and figures.
\end{abstract}

Result: A total of 622 participants were included in the analysis which makes a response rate of $99.9 \%$. Prevalence of intestinal parasites was $48.7 \%(95 \% \mathrm{Cl}, 44.8-52.6)$ in this study. Higher family size ( $\mathrm{AOR}=2.7,95 \% \mathrm{Cl}=1.5-5.0)$, medium family size ( $A O R=2.3,95 \% \mathrm{Cl}, 1.3-4.2)$, absence of laterine facility in the household ( $A O R=2.9,95 \% \mathrm{Cl}=1.6-5.3$ ), unable to put on shoes ( $A O R=3.5,95 \% \mathrm{Cl}=2.2-5.7)$, and eating raw vegetables $(\mathrm{AOR}=2.6,95 \% \mathrm{Cl}=1.6-4.7)$ were factors positively associated with intestinal parasites in this study.

Conclusion: Overall prevalence of intestinal parasites was almost high. Latrine facility, family size, shoes wearing habit and eating raw vegetables were significantly associated with intestinal parasites. Family planning service, sanitation and hygiene practices should be intensified through community education. Activate support of deworming program should be considered. Moreover, policy makers should give priority on creating awareness to prevent intestinal parasite.

Keywords: Intestinal parasites, Children, 6 to 59 months, Ethiopia

\footnotetext{
* Correspondence: birieman67@gmail.com

${ }^{1}$ Department of Midwifery, college of medicine and health sciences, Hawassa

University, Hawassa, Ethiopia

Full list of author information is available at the end of the article
}

(c) The Author(s). 2020 Open Access This article is distributed under the terms of the Creative Commons Attribution 4.0 International License (http://creativecommons.org/licenses/by/4.0/), which permits unrestricted use, distribution, and reproduction in any medium, provided you give appropriate credit to the original author(s) and the source, provide a link to the Creative Commons license, and indicate if changes were made. The Creative Commons Public Domain Dedication waiver (http://creativecommons.org/publicdomain/zero/1.0/) applies to the data made available in this article, unless otherwise stated. 


\section{Background}

Intestinal parasites are inhabitants of gastro-intestinal tract. They can cause malnutrition on different population groups. Children and poor people are the most vulnerable groups since they have more chance of contact with contaminated soil in their daily life [1]. Poor personal hygiene and lack of clean water are the main causes of intestinal parasites. Intestinal parasites could exist predominantly in polluted, overcrowded and dirty places [2]. Intestinal parasites are manifested by diarrhea, abdominal cramp, vomiting and weight loss. These symptoms can be more severe among children, under nourished and immune compromised patients than other group of population [3-5]. Diarrhea is a predominant consequence of intestinal parasites. It is the leading cause of mortality and morbidity of under five children [6-8]. In addition, it can aggravate protein energy malnutrition, anemia and other nutrient deficiencies [9]. Moreover, intestinal parasites have been associated with short and long term complications on children. These include the following health complications: stunting, physical weakness, insufficient educational achievement, poor reproductive health, and low economic development $[10,11]$.

Intestinal parasites are the most prevalent infections among children of poor and rural families since they have contacts with soil on their farm in most of the time. So, children are more prone for infective larvae through direct or indirect transmission route [1]. Children of under-five years of age are the most vulnerable group due to their low immunity status. Hence, they need special care and follow up [12]. Despite the existence of different prevention strategies like, chemotherapy and health promotion, intestinal parasites are a widely spread problem in the world [13]. According to Ethiopia Schistosomiasis and soil-transmitted Helminthes control program report, there is a short term target of reduction of the current heavy and moderate soil transmitted helminthic infection intensity to less than $1 \%$ at the end of the program in Ethiopia [14]. But, a study conducted in Babile town, Eastern Ethiopia shows that prevalence of intestinal helminthes is $27.2 \%$ [15]. A. lumbricoides and T. trichiura are the commonest and widely distributed parasites throughout Ethiopia [16]. Besides, protozoa are the other dominant infections which exert huge impact in Ethiopia [4].

When prevalence of intestinal parasites is less than $20 \%$, it is considered as lowest. Moreover, it is considered as moderate when it is from 20 to $50 \%$. It is also classified as heavy when the prevalence is greater than $50 \%$ [17]. The long term global target is to eliminate mortality and morbidity associated with intestinal parasites among children by 2020 [18]. According to Boricha health office report, intestinal parasites affect almost all
Kebeles of the district. Preventive and curative actions were performed. Among these, all school age children were dewormed every two to five years regularly. The commonest type of toilet was a pit latrine without a slab or open pit in the district [19]. Farming activity is the main source of income in Boricha district; inhabitants of district mainly produce Enset, cash crops (khat, coffee) and livestock. Unclean drinking water source, poor hygienic condition and frequent drought in the district results high burden of the under-nutrition and intestinal parasites [20]. Poor hygiene related diseases, like acute watery diarrhea and intestinal parasites, are among the leading causes of childhood morbidity and mortality [19]. Although many studies have been conducted about intestinal parasites in Ethiopia [21, 22]. Information is scarce in the current study area about intestinal parasites among children of age 6 to 59 months. Moreover, most previous studies were focused on school aged children but studies were limited among children aged 5 to 59 months. Therefore, the main aim of this study is to assess prevalence and factors associated with intestinal parasite infections among children of 6 to 59 months in Boricha district, South Ethiopia, in 2018.

\section{Methods}

\section{Study area}

The study was carried out at Boricha district, Sidama zone, South Ethiopia. It is located $206 \mathrm{~km}$ from Addis Ababa, the capital city of Ethiopia, and $32 \mathrm{~km}$ from Hawassa main city of Southern nation nationalities and peoples of Ethiopia. According to the 2018 Ethiopian central statistical agency report, the total population of the district was estimated to be 325,636 . From these, nearly all (97\%) population live in rural area. Children of 6 to 59 months' age account of $13.94 \%$ of the population. Boricha consists of 4 urban and 39 rural Kebeles. The health service coverage of the district was $85 \%$. It has one government district hospital, ten health centers, thirty-nine health posts and eight private clinics.

\section{Study design, period and population}

Community based cross sectional study was carried out in Boricha district from January 1st to 30th, 2018. The source population were all children aged 6 to 59 months who live in Boricha district. The study population were children aged 6 to 59 months who lived in randomly selected household. Those children whose family lived less than 6 months, took preventive chemotherapy (deworming), and treated recently for intestinal parasites were excluded from this study.

\section{Sample size determination and sampling technique}

Sample size was calculated by using single population proportion formula in consideration of the following 
assumptions: The prevalence of intestinal parasites was taken as $24.3 \%$ [23], 95\% confidence level, $5 \%$ margin of error. Thus, $\mathrm{n}=\mathrm{z}^{2} \mathrm{pq} / \mathrm{d}^{2}$. Then, $n=1.96^{2 *} 0.243(0.757) /$ $0.05=283$. By using a design effect of 2 and adding $10 \%$ non-response rate, a total sample sizes of 624 were included. Boricha was selected intentionally by considering its context of exposure for intestinal parasites and lack of previous research related to the problem. There are 43 Kebeles in the district. Of these, 4 were urban and 39 were rural Kebeles. A two stage sampling technique was applied to select the representative sample size of this study. Firstly, eight Kebeles were selected using simple random sampling based on their proportion of place of residence which satisfy $20-30 \%$ of the total district Kebeles. Secondly, a sampling frame was prepared through census. It consisted of lists of household in the selected Kebeles. There were a total of 8482 children in the selected Kebeles. The calculated sample interval (K= $\mathrm{N} / \mathrm{n}$ ) was 14 . Then, systematic random sampling strategy was used to select the study participants. The first child was identified by using simple random sampling strategy by using lottery method. Then, consecutive children were selected at a regular interval of 14th household. If there was no child from the household for consecutive visits, the next nearest child was included. One child was included by using lottery method when more than one child was present selected households. Each child was given a unique identifier to be identified during the socio-demographic and stool examination.

\section{Study variables}

In the current study, the outcome variable was presence of intestinal parasites. It is a binary outcome variable. Independent variables included socio-demographic, environmental and health seeking behavior variables. Sociodemographic variables included the following variables: age and sex of child, religion, ethnicity, family size, wealth index, maternal/paternal education and occupation, marital status and media availability. Environmental variables consisted of variables like, water source, availability of latrine, availability of safe excreta disposal, type of house and numbers of room. Health-seeking behavior variables included the following variables: personal hygiene practice, type of water consumption, water handling technique, hand washing practice, playing with soil, habit of eating raw vegetables and fruits and wearing shoes, health service availability, household food insecurity status and dietary diversity score.

\section{Operational definition}

Intestinal parasite Is present when a child is infected with at least one intestinal parasite infection.
Family size Family size is defined as a total number of family members living in the household. Family size is classified as small when it is less than six. It is classified as medium when it is between six to eight, and it is classified as large when it is greater than eight.

\section{Data collection method and tools}

Data were collected by face to face interview using a structured and pre-tested questionnaire. Data were collected in Sidama language from children's parents (caregivers). Interviewers have also inspected whether children wore shoe or not. Data were collected by eight diploma nurses, two laboratory technicians, and eight community health workers. Two health officers supervised data collection process.

\section{Stool collection and examination}

All parents / guardians/ were informed by health extension workers to bring their children of age 6 to 59 months to health posts. Parents or guardians were asked to provide about $2 \mathrm{~g}$ of fresh stool sample of their children using clean, tightly corked, leak proof containers. The sample was analyzed using wet mount technique and the remaining portion was concentrated using formal ether concentration technique [24]. The specimens were examined microscopically for the presence of eggs, trophozoites or cysts. Stool samples were collected from 622 children whose age was between 6 to 59 months for intestinal parasites examination.

\section{Data quality control}

Questionnaire was prepared in English language, and translated into Sidama language (local language). Then, it was re-translated back to English to keep its consistency. Comparison was done between two versions to assess inconsistent and inaccurate data. It was pre-tested by $5 \%$ of sample size in Kebeles which were not included in the actual study area. Finally, any inconsistent and inaccurate data was re-adjusted accordingly. Data collectors and supervisors were given two-day training before the actual data collection time. The training was focused on the aim, procedure and data collection technique.

\section{Data processing and analysis}

Data were cleaned, coded and entered in to a computer using Epi data. Then, data were exported and analyzed by SPSS version 22. Descriptive statistics was used to show prevalence of intestinal parasites. Tables and graphs were formed to present data. Binary logistic analysis was done first and variables with $p$-value $<0.25$ were considered as candidate for multivariable logistic regression. Model fitness was checked using HosmerLemeshow test of goodness of fit before the actual logistic regression analysis. Adjusted Odds Ratio (AOR) with 
95\% confidence interval (CI was reported. Variables which have $P$-value of less than 0.05 in the multivariable logistic regression analysis was considered as significantly associated factors of intestinal parasites. Finally, those variables whose $p$-value less than 0.05 were considered as statistically significant in multi-variable logistic regression.

\section{Results}

Table 1 presents socio-demographic characteristics of study subjects. From a total of 624 children who participate in this study, children who gave full response were 622 making a response rate of $99.9 \%$. Mean age of children was 29.25 months. Nearly 510 (82\%) of households got their income from farming activities. Four-hundredone (64.4\%) and three-hundred- four (63.3\%) of the parents never attended formal education. The studied households had a median family size of approximately six persons. Almost all of the households 614(98.7\%) were headed by males. The two hundred-forty-two (38.9\%) of the households had access to mass media (insert Table.1).

Households which got protected water sources were 485 (78\%). The majorities (67.5\%) of the study households had pit latrines without a slab. Two-hundred fiftytwo $(40.4 \%)$ of children did not wear shoes. The majorities $(65.8 \%)$ of households used a single room to sleep (insert Table.2).

\section{Prevalence of intestinal parasites among children of age 6 to 59 months}

Giardiasis 255(41\%) and ascariasis 280(45\%) were common parasites among females. However, trichuriasis 180(27\%) and hookworm 205(33\%) were common among males. The overall prevalence of at least one intestinal parasite was $48.7 \%$ (95\% CI, 44.8-52.6). The prevalence of protozoa was, Giardia lamblia 65(10.45\%) and Entamoeba histoltica 29(4.66\%). In addition, helminthes were, A. lumbricoides 67 (10.77\%), Hookworm 49 (7.88\%), T. trichiura 38 (6.1\%), S. stercoralis 10 (1.6\%) and Tinea species 8 (1.3\%). Mixed infections accounted for 37 (5.94\%) of children (insert Table.3).

\section{Determinants of intestinal parasites}

Results of multivariable logistic regression analysis are shown in Table 4. Accordingly, wealth index, main source of drinking water, eating raw vegetables, absence of latrine, wearing shoe and family size were factors significantly associated with intestinal parasites. Children from large family size (more than eight family member) had 2.7 fold of higher odds of intestinal parasites than children from lower family size $(\mathrm{AOR}=2.70 ; 95 \% \mathrm{CI}=1.5-5.0, P=0.001)$. In addition, children from medium family size (six to eight) had 2.3 more chance of infection than children of lower family size
Table 1 Socio-demographic characteristics of study participants in Boricha district, South Ethiopia, $2018(n=622)$

\begin{tabular}{|c|c|c|}
\hline Variables & Categories & $\begin{array}{l}\text { Number } \\
(\%)\end{array}$ \\
\hline \multirow[t]{2}{*}{ Sex of child } & Male & $305(49 \%)$ \\
\hline & Female & $317(51 \%)$ \\
\hline \multirow[t]{3}{*}{ Age of child } & 6-11 months & $\begin{array}{l}105 \\
(24.5 \%)\end{array}$ \\
\hline & 12-23 months & $\begin{array}{l}126 \\
(20.3 \%)\end{array}$ \\
\hline & 24-59 months & $\begin{array}{l}343 \\
(55.2 \%)\end{array}$ \\
\hline \multirow[t]{2}{*}{ Ethnicity } & Sidama & $\begin{array}{l}596 \\
(95.8 \%)\end{array}$ \\
\hline & Others & $26(4.2 \%)$ \\
\hline \multirow[t]{2}{*}{ Religions } & Protestant & $\begin{array}{l}517 \\
(83.1 \%)\end{array}$ \\
\hline & Others & $\begin{array}{l}105 \\
(16.9 \%)\end{array}$ \\
\hline \multirow[t]{3}{*}{ Family size } & Small & $\begin{array}{l}300 \\
(48.2 \%)\end{array}$ \\
\hline & Medium & $\begin{array}{l}117 \\
(18.8 \%)\end{array}$ \\
\hline & Large & 205 (33\%) \\
\hline \multirow[t]{3}{*}{ Maternal educational status } & No formal education & $\begin{array}{l}401 \\
(64.4 \%)\end{array}$ \\
\hline & Primary education & $159(25.6)$ \\
\hline & $\begin{array}{l}\text { Secondary education \& } \\
\text { above }\end{array}$ & $62(10 \%)$ \\
\hline \multirow[t]{3}{*}{ Paternal educational status } & No formal education & $\begin{array}{l}394 \\
(63.3 \%)\end{array}$ \\
\hline & Primary education & $\begin{array}{l}122 \\
(19.6 \%)\end{array}$ \\
\hline & $\begin{array}{l}\text { Secondary education \& } \\
\text { above }\end{array}$ & $106(17.1)$ \\
\hline \multirow[t]{2}{*}{$\begin{array}{l}\text { The main occupation of the } \\
\text { head }\end{array}$} & Farmer & $\begin{array}{l}505 \\
(81.2 \%)\end{array}$ \\
\hline & Daily worker & $\begin{array}{l}117 \\
(18.8 \%)\end{array}$ \\
\hline \multirow[t]{5}{*}{ Wealth Index } & Poorest & $\begin{array}{l}154 \\
(24.8 \%)\end{array}$ \\
\hline & Poor & $72(11.6 \%)$ \\
\hline & Middle & $\begin{array}{l}157 \\
(25.2 \%)\end{array}$ \\
\hline & Rich & $\begin{array}{l}117 \\
(18.8 \%)\end{array}$ \\
\hline & Richest & $\begin{array}{l}122 \\
(19.6 \%)\end{array}$ \\
\hline
\end{tabular}

$(\mathrm{AOR}=2.3,95 \% \mathrm{CI}, 1.3-4.2, p=0.03)$. The likelihood of getting intestinal parasites among children who had a habit of eating raw vegetables was 2.6 times higher than their counterparts $(\mathrm{AOR}=2.65,95 \mathrm{CI}=1.60-4.70, P=0.002)$. The odds of infection by intestinal parasites among children 
Table 2 The sanitation and personal hygiene condition of studied children aged 6-59 months, Boricha District, Southern Ethiopia, $2018(n=622)$

\begin{tabular}{lll}
\hline Variable & Categories & No (\%) \\
\hline The main source of drinking & Protected & $485(78 \%)$ \\
water & Unprotected & $137(22 \%)$ \\
Availability of toilet facility & yes & $449(72.2 \%)$ \\
Nypes of latrine & Pit latrine without & $420(67.5 \%)$ \\
& slab & \\
Number of rooms used to sleep & One latrine with slab & $29(4.7 \%)$ \\
& Two & $408(65.8 \%)$ \\
Hand washing practice & Yes & $214(34.2 \%)$ \\
& no & $394(63.3 \%)$ \\
Shoes wearing habit & Yes & $228(36.7 \%)$ \\
& & 371 \\
Practice of eating raw vegetable & Yes & $251(40.4 \%)$ \\
& No & $184(29.6 \%)$ \\
\hline
\end{tabular}

living in the household with absence of latrine were 2.9 times higher than their counterparts $(\mathrm{AOR}=2.9 ; 95 \% \mathrm{CI}=$ 1.60-5.30, $P=0.001$ ). Unable to wore shoes, in contrast to wearing shoes showed an increased odds of infection by intestinal parasites $(\mathrm{AOR}=3.5 ; 95 \% \mathrm{CI}=2.20-5.70, \mathrm{P}=0.001)$ (insert Table.4).

\section{Discussion}

Prevalence of intestinal parasite infection was $48.7 \%$ (95\%CI, 44.8-52.6) in this study. Larger family size, medium family size, absence of laterine, unable to put on shoe, eating raw vegetable were factors positively associated with intestinal parasites. When the prevalence of intestinal parasite was reached to $50 \%$ and above, it is considered as high in Ethiopia. According to national

Table 3 prevalence of intestinal parasites among children of age 6-59 months in Boricha district, Southern Ethiopia, 2018 $(n=622)$

\begin{tabular}{lll}
\hline Variable & Categories & No (\%) \\
\hline Types of infections & Single & $266(42.8 \%)$ \\
& Mixed & $37(5.9 \%)$ \\
Types of intestinal parasites & Giardia lamblia & $65(10.45 \%)$ \\
& Entamoeba histoltica & $29(4.66 \%)$ \\
& Ascaris lumbricoides & $67(10.77 \%)$ \\
& Trichiuris trichiuria & $38(6.1 \%)$ \\
& Hookworm & $49(7.88 \%)$ \\
& Tinea species & $8(1.3 \%)$ \\
& Strongliod stercorias & $10(1.6 \%)$ \\
\hline
\end{tabular}

classification of intestinal parasite prevalence, the finding of the current study is reached to high category [17]. In addition, it is far from short term national target reduction of intestinal parasite of less than 1\% in Ethiopia. So, it is impossible to meet national target of eliminating parasites in 2020 [14]. This finding is consistent with a study conducted in Hawassa Zaria,South Ethiopia (51.3\%) and Senbete town,North Shoa,Ethiopia (52.3\%) $[25,26]$. The possible explanation might be due to similarities of certain characteristics parents of children in the current study and studies mentioned above. These include the following factors: socio-economic status, level of awareness about the problem and life styles. Besides, it may be due to similar study population in these studies. This finding is higher than findings of studies conducted in Wonji Shoa Sugar Estate, Ethiopia (24.3\%) [23] and Hawassa, South Ethiopia (26.6\%) [27]. This might be explained by a number of factors. They were low socio-economic condition, specific climate, poor sanitary and hygiene condition in the current study area. On the contrary,this finding is lower than finding of a study conducted in Addis Ababa, Ethiopia (71.8\%) [28]. The possible rational for this difference might be due to good personal hygiene practice and better life style modification like, good food handling was better among children in the current study than children in the above study. Moreover, better awareness was created about the problem among parents of children in the current study.

According to report of this study, the habit of eating raw vegetable was positively associated with intestinal parasites. This finding is consistent with finding of a study conducted in Thailand, Itabuna [29]. The possible explanation might be that study participants eat raw vegetables and fruits without washing their hands. This rational is enhanced by the fact that green vegetables and fruits are the main source of food in both study areas. Participants might handle and utilize vegetables with unhygienic matter without washing them. This study also indicated that the absence of household latrine was associated with intestinal parasites positively. Similar findings were reported from studies conducted in Senbete and Bete towns, North Shoa, Ethiopia and Tseda health center North West Ethiopia [26, 30]. This might be due to contamination of water and food with human waste during open field defecation. Besides, lack of awareness about importance of hand washing practice after defecation can lead to easily contaminate people through food. In addition, open field defection could increase parasite infection. Ethiopians, especially people in this study area, have a habit of eating raw meat. Hence, cattle meat is contaminated by people's defecation during grassing. Shoe wearing practice was another important and statically significant factor in the current study. This result was consistent with studies conducted in North 
Table 4 Determinant of intestinal parasitic infections from backward stepwise (Wald) logistic regression in among children aged 6 to 59 months, Boricha district, South Ethiopia, $2018(n=622)$

\begin{tabular}{|c|c|c|c|c|c|c|}
\hline \multirow[t]{2}{*}{ Variable } & \multirow[t]{2}{*}{ Categories } & \multicolumn{2}{|c|}{ Intestinal parasites } & \multirow[t]{2}{*}{$\operatorname{COR}(95 \% \mathrm{Cl})$} & \multirow[t]{2}{*}{$\mathrm{AOR}(95 \% \mathrm{Cl})$} & \multirow{2}{*}{$\begin{array}{l}p- \\
\text { value }\end{array}$} \\
\hline & & Yes & No & & & \\
\hline \multirow[t]{5}{*}{ Wealth index } & Poorest & 113 & 41 & $5.65(3.35,9.5)^{*}$ & $1.04(0.49,2.22)$ & 0.62 \\
\hline & Poor & 39 & 33 & $2.42(1.33,4.4)^{*}$ & $0.79(0.34,1.78)$ & 0.57 \\
\hline & Middle & 69 & 88 & $1.6(0.98,2.62)$ & $0.57(0.29,1.10)$ & 0.72 \\
\hline & Rich & 42 & 75 & $1.14(0.67,1.95)$ & $0.57(0.28,1.15)$ & 0.64 \\
\hline & Richest & 40 & 82 & 1 & 1 & \\
\hline \multirow[t]{2}{*}{ Source of drinking water } & Protected & 199 & 286 & 1 & 1 & \\
\hline & Unprotected & 104 & 33 & $4.52(3.13,7.62)^{*}$ & $1.14(0.58,2.24)$ & 0.351 \\
\hline \multirow[t]{2}{*}{ Raw vegetables \& fruits } & Yes & 143 & 41 & $6.0(4.07,9.02)^{*}$ & $2.65(1.6,4.7)^{* *}$ & 0.002 \\
\hline & No & 160 & 278 & 1 & 1 & \\
\hline \multirow[t]{2}{*}{ Absence of latrine } & Yes & 135 & 38 & $5.9(4,8.9)^{*}$ & $2.9(1.6,5.3)^{* *}$ & 0.001 \\
\hline & No & 168 & 281 & 1 & 1 & \\
\hline \multirow[t]{2}{*}{ Wearing Shoes } & Yes & 127 & 244 & 1 & 1 & \\
\hline & No & 176 & 75 & $4.5(3.2,6.4)^{*}$ & $3.5(2.2,5.7)^{* *}$ & 0.001 \\
\hline \multirow[t]{3}{*}{ Family size } & Small & 78 & 222 & 1 & 1 & \\
\hline & Medium & 71 & 46 & $4.4(2.8,6.9)^{*}$ & $2.3(1.3,4.2)^{* *}$ & 0.03 \\
\hline & Large family & 154 & 51 & $8.6(5.7,12.9)^{*}$ & $2.7(1.5,5)^{* *}$ & 0.001 \\
\hline
\end{tabular}

Key: 1 = reference categories; ${ }^{*}=$ Indicates significant association $(P$-value $<0.25) ;{ }^{* *}=$ Indicate the highly significant association $(P$-value $<0.05)$; COR Crude Odds Ratio, AOR Adjusted Odds Ratio, Cl Confidence Interval

West Ethiopia [30]. This might be that parents of children were not informed about mode of transmission of parasites. Besides, children who walk on barefoot allowed penetration of their skin by the infective parasites. The current study also revealed that children live in large family size (more than eight) were positively associated with intestinal parasitic infections than children live in small family size. Similar finding reported from a study conducted in the Tigray region of Ethiopia [32]. This might be due to the fact that overcrowded family condition creates an increased opportunity for parasitic transmission. In addition, parents may not have time to care their child.

\section{Limitation of the study}

This study had a number of strengths. Among these strengths, the community based nature of this study is representative of all children in the age group of 6 to 59 months which is essential in appropriate policy strategy for effective prevention of intestinal parasites. Regardless of its strengths, this study had few limitations. First, due to a cross-sectional design, it was difficult to examine any potential temporal relationships. Second, there might be a recalling bias for some study variables. Finally, children are only recruited within a single month, and there may be seasonal fluctuations of the prevalence of intestinal parasite in the study area.

\section{Conclusion}

This study demonstrated that prevalence of intestinal parasites is still high among children of age 6 to 59 months. The absence of latrine facility, habit of eating raw vegetables, large family size and unable to wear shoes were factors positively associated with intestinal parasites. Policy makers should give priority for personal hygiene and environmental sanitation. In addition, awareness creation should be enhanced on life style modification for prevention of intestinal parasite infections.

\section{Abbreviations}

AOR: Adjusted Odds Ratio; Cl: Confidence Interval; IRB: Institutional Review Board; SPSS: Statistical Package for Social Science

\section{Acknowledgements}

The authors would like to pass their gratitude to Hawassa University for the approval of ethical clearance. We would like to extend our thanks to Southern health bureau, Boricha health office and respected Kebeles. The authors are also very grateful for data collectors and study participants. Our deep gratitude goes to Dr. Tarekegn Yoseph for his support. Finally, our special thanks go to Abebech Damasa for her genuine psychological support.

\section{Authors' contributions}

AY involved in initiation of the research question, prepared the research proposal, carried out the research, entered and analyze data and wrote the manuscript. HB conducted edition, advising, cooperatively prepared research tools and revised the manuscript. BT conceived, entered and analyze data, interpret data and drafted the final report. He wrote up and prepared manuscript. All authors read and approved the final manuscript. 


\section{Funding}

The is no funding source for this study.

\section{Availability of data and materials}

We have sent all the available data and we do not want to share the raw data as we are doing related study.

\section{Ethics approval and consent to participate}

Ethical clearance was obtained from Hawassa university institutional review Board with a reference number of IRB/143/10. Parents or caregivers were clearly explained about the objective and scope of study. Data were collected after parents or caregivers signed written consent. Children were referred for treatment if their stool test is positive.

\section{Consent for publication}

Not applicable.

\section{Competing interests}

All authors declare that they have no competing interests.

\section{Author details}

${ }^{1}$ Department of Midwifery, college of medicine and health sciences, Hawassa University, Hawassa, Ethiopia. ${ }^{2}$ Department of public health, college of medicine and health sciences, Hawassa University, Hawassa, Ethiopia. ${ }^{3}$ Department of Environmental, College of Medicine and Health Sciences, Hawassa University, Hawassa, Ethiopia.

Received: 19 September 2019 Accepted: 16 January 2020

Published online: 22 January 2020

\section{References}

1. Organization, W.H., Soil-transmitted helminthiases: eliminating as public health problem soil-transmitted helminthiases in children: progress report 2001-2010 and strategic plan 2011-2020. 2012.

2. Shrestha A, Narayan K, Sharma R. Prevalence of intestinal parasitosis among school children in Baglung District of Western Nepal. Kathmandu Univ Med J. 2012;10(1):62-5.

3. Abera A, Nibret E. Prevalence of gastrointestinal helminthic infections and associated risk factors among schoolchildren in Tilili town, Northwest Ethiopia. Asian Pac J Trop Med. 2014;7(7):525-30.

4. Getaneh A, Medhin G, Shimelis T. Cryptosporidium and Strongyloides stercoralis infections among people with and without HIV infection and efficiency of diagnostic methods for Strongyloides in Yirgalem hospital, southern Ethiopia. BMC Res Notes. 2010;3(1):90.

5. Mathewos B, et al. Current status of soil transmitted helminths and Schistosoma mansoni infection among children in two primary schools in North Gondar, Northwest Ethiopia: a cross sectional study. BMC Res Notes. 2014;7(1):88

6. UNICEF And W. Diarrhoea, why children are still dying and what can be done. New York: UNICEF; 2009.

7. Sergio JV, Leon AC. Analysis of mortality from diarrheic diseases in underfive children in Brazilian cities with more than 150,000 inhabitants. Cadernos de saúde pública. 2009;25(5):1093-102.

8. Mandomando $\mathbf{I M}$, et al. Etiology of diarrhea in children younger than 5 years of age admitted in a rural hospital of southern Mozambique. Am J Trop Med Hygiene. 2007;76(3):522-7.

9. Lwanga F, Kirunda BE, Orach CG. Intestinal helminth infections and nutritional status of children attending primary schools in Wakiso District, Central Uganda. Int J Environ Res Public Health. 2012;9(8):2910-21.

10. Uhuo A, Odikamnoro $\mathrm{O}$, Ani $\mathrm{O}$. The incidence of intestinal nematodes in primary school children in Ezza north local government area, Ebonyi state Nigeria. Adv Appl Sci Res. 2011;2(5):257-62.

11. Heidari A, Rokni M. Prevalence of intestinal parasites among children in daycare centers in Damghan-Iran. Iran J Public Health. 2003:31-4.

12. Valiathan $R$, Ashman $M$, Asthana $D$. Effects of ageing on the immune system: infants to elderly. Scand J Immunol. 2016;83(4):255-66.

13. Organization, W.H., Soil-transmitted helminthiasis: Number of children treated 2007-2008: Update on the 2010 global target: background. Weekly Epidemiological Record= Relevé épidémiologique hebdomadaire, 2010 85(16): p. 141-147.
14. Ethiopia, F.D.R.o. and M.o. Health, Second Edition of National Neglected Tropical Diseases Master Plan Addis Ababa, 2016. 2016.

15. Tadesse $\mathrm{G}$. The prevalence of intestinal helminthic infections and associated risk factors among school children in Babile town, eastern Ethiopia. Ethiop J Health Dev. 2005;19(2):140-7.

16. Ayalew A, Debebe T, Worku A. Prevalence and risk factors of intestinal parasites among Delgi school children, North Gondar, Ethiopia. J Parasitol Vector Biol. 2011;3(5):75-81.

17. Federal Ministry of Health, E., Federal Democratic Republic of, Second Edition of National Neglected Tropical Diseases Master Plan Addis Ababa, 2016. 2016.

18. Organization, W.H., Fact Sheet: Soil-Transmitted Helminth Infections [WWW Document]. WHO. Available online at: http://www.who.int/mediacentre/ factsheets/fs366/en(accessed 3.27. 17), 2017.

19. Boricha woreda Health office. Annual District Health and Health related report. Boricha: Woreda Health office; 2009.

20. Boricha woreda water office. Annual water and sanitations report. Boricha: Boricha woreda water office; 2009.

21. Tedla S, Jemaneh L. Distribution of Ancylostoma duodenale and Necator americanus in Ethiopia. Ethiop Med J. 1985:23(4):149-58.

22. Zein ZA, Assefa M. The prevalence of intestinal parasites among farming cooperatives, Gondar region, North-Western Ethiopia. Ethiop Med J. 1985; 23(4):159.

23. Degarege A, Erko B. Prevalence of intestinal parasitic infections among children under five years of age with emphasis on Schistosoma mansoni in Wonji Shoa sugar estate, Ethiopia. PloS One. 2014;9(10):e109793.

24. Adefioye $\mathrm{OA}$, et al. Intestinal helminthiasis among school children in Ilie, Osun state, southwest, Nigeria. Sierra Leone J Biomed Res. 2011;3(1):43-8.

25. Alemneh Kabeta, et al., Intestinal parasitic infections and nutritional status of pre-school children in Hawassa Zuria District, South Ethiopia. African Journal of Microbiology Research, July, 2017.

26. Moges Lewetegn, Prevalence of intestinal parasites among preschool children and maternal knowledge, attitude and practice on prevention and control of intestinal parasites in Senbete and Bete towns, North Shoa, Ethiopia. November, 2015.

27. Mulatu G, Beyene G, Zeynudin A. Prevalence of Shigella, Salmonella and Cmpylobacter species and their susceptibility patters among under five children with diarrhea in Hawassa town, South Ethiopia. Ethiop J Health Sci. 2014;24(2):101.

28. Mekonnen, B., B. Erko, and M. Legesse, Prevalence of intestinal parasitic infections and related risk factors among street dwellers in Addis Ababa, Ethiopia. Journal of Tropical Diseases \& Public Health, 2014.

29. Boonchai Wongstitwilairoong, et al., Intestinal parasitic infections among pre-school children in Sangkhlaburi, Thailand. The American journal of tropical medicine and hygiene, November 2014

30. Abraraw Abate, et al., Cross-sectional study on the prevalence of intestina parasites and associated risk factors in Teda health Centre, Northwest Ethiopia. Hindawi Publishing Corporation, ISRN Parasitology, 2013.

\section{Publisher's Note}

Springer Nature remains neutral with regard to jurisdictional claims in published maps and institutional affiliations.

Ready to submit your research? Choose BMC and benefit from:

- fast, convenient online submission

- thorough peer review by experienced researchers in your field

- rapid publication on acceptance

- support for research data, including large and complex data types

- gold Open Access which fosters wider collaboration and increased citations

- maximum visibility for your research: over $100 \mathrm{M}$ website views per year

At $\mathrm{BMC}$, research is always in progress.

Learn more biomedcentral.com/submissions 